\title{
Observer-based Linear Control of Synchronous Machine with Damper and Excitation Winding
}

\author{
Marijo Šundrica ${ }^{1}$, Miroslav Petrinić ${ }^{2}$ \\ ${ }^{1}$ Končar Power Plant and Electrical Traction Engineering, Fallerovo šetalište 22, \\ 10000 Zagreb, Croatia, marijo.sundrica@ koncar-ket.hr \\ ${ }^{2}$ Končar Electrical Engineering Institute, Fallerovo šetalište 22, 10000 Zagreb, \\ Croatia, mpetrinic@ @oncar-institut.hr
}

Abstract: This paper proposes a novel control system for synchronous machine rotor speed control. Based on deterministic observer and cascaded loops, a linear control system is obtained. Stability proof of the observer and linear analysis of the control system is given. Simulation studies of the machine starting, speed reversal and step loading are presented. A Comparison Analysis with the nonlinear control method, is also presented.

Keywords: synchronous machine; observer; linear control; nonlinear control

\section{Introduction}

The scope of this work is synchronous machine operation as an AC drive system. Synchronous machine (SM) is considered in its full complexity: saliency, excitation and damper windings. There is need for an AC drive system with this kind of SM when variable speed operation is requested. Whenever the frequency converter is connected with the SM, its control has to be designed. This occurs in hydropower, wind power, industrial applications (fan, compressor, conveyor belt) and in propulsion systems. By changing amplitude, frequency and vector position of the supplied voltage, rotor speed (or electromagnetic torque) and magnetic flux are controlled. Obtaining adequate control system for such SM is very challenging and there are not many research studies either with linear or nonlinear control systems.

In classical linear control system [1], dynamics of the damper winding currents are neglected. Calculation of magnetic fluxes has not stability proof. Consequently, it is possible for the drive system to become unstable. Due to this, classical SM drive system needs three control variables to obtain the control of two outputs. The control variables are stator voltage components $u_{d}$ and $u_{q}$, and excitation winding voltage $u_{f}$. The output (controlled) variables are only two: rotor speed or 
electromagnetic torque, and magnetic flux. Except form that, decoupling between rotor speed and magnetic flux control is hard to obtain by the classical system [2]. Due to this, instead of rotor flux orientation, stator flux orientation control system is obtained [3-7]. However, [3-7] lack in stability proof of the controller. Whether DTC [8] or vector control principles are used, three control inputs are always in use and damper winding current dynamics are always neglected. Regarding nonlinear control of the SM, there are few studies [9-10] in which mathematically proved control law is obtained without neglecting complexities of the SM dynamical system. In [9-10], again three control variables have to be used. In [1112], two control variables are used, but obtained control law needs to be predictive. Except from that, the control law strongly depends on load torque. Although a load torque estimation algorithm has been given [11-12], it could be seen that load torque estimation relay upon calculation of the electromagnetic torque. Literature [11-12] also use feedback linearization method. Taking all of that into consideration, there might be significant loss of precision due to parameter variation in the case [11-12] is used in praxis.

Except from motor control, literature review of the control system principles used in various industrial applications is also done. State space representation of the controlled plant is the starting point of the control system design even when the plant is nonlinear [13]. To obtain the precise control using linear control techniques, usually cascaded control system with inner and outer control loops is designed [14]. If the plant model is well known, some advanced control methods such as modified shared circuit model (MSCM) [15] or already known internal model control (IMC) could be used to obtain the controller parameters. Literature also gives vast number of artificial intelligence methods such as neural networks used in control system applications [16] [17]. Stability of the robot control applications is proved by the Lyapunov function [18]. If a dynamical system of the controlled plant is not known, various data driven algorithms have been developed. In [19], data driven CFDL-PDTSFA algorithm is used to obtain the tower crane control.

In this work, a novel linear control method for the SM control is presented. Because SM model and its identification is known, starting point of the control design is state space representation. To obtain the complete state vector, an observer for the damper winding has to be designed. Stability of the observer is proved by Lyapunov function. Linear control principles are used and cascaded control system is designed. Design of the inner control loops use IMC principle. In comparison with classical linear control, some improvements have been made. At first, deterministic observer for the damper winding states have been given and used in obtaining decoupled control. Finally, a control system needs only two control inputs. Regarding nonlinear control systems, novel linear control does not need load torque estimation and generally is less dependent on SM parameter variation. In addition, novel linear control does not need any a priori knowledge of reference values. 
After the introduction with literature review, a novel deterministic observer is given in Chapter 2. Dynamical system and its stability proven observer are presented there. Using this observer, linear control system is obtained and described in Chapter 3. Its complete control scheme as well as its inner and outer control loops are presented. Parameter tuning is also given. Then, an extensive simulation study is given in Chapter 4. Starting, speed reversal and step loading of the chosen SM is done. Comparative analysis between the novel and the known observer and between the novel and the known nonlinear control system are included. Finally, conclusion with main contributions and discussion is also given.

\section{Deterministic Observer}

\subsection{Dynamical System}

In the [11-12] SM model with damper winding fluxes is given. Observability of the damper winding fluxes have been proved and various observers are presented. Full order observers need information about load torque. Reduced order observer does not have any convergence coefficients and is practically a pure integration. In the case of parameter variation, reduced order observer will lose its precision. Due to this, a novel observer is obtained. From the SM model [11] [12] with damper winding fluxes the following dynamical equations are extracted:

$$
\begin{gathered}
\frac{d i_{d}}{d t}=a_{1} i_{d}+a_{2} i_{f}+a_{3} i_{q} \omega+a_{4} \psi_{D}+a_{5} \psi_{Q} \omega+a_{6} u_{d}+a_{7} u_{f} \\
\frac{d \psi_{D}}{d t}=c_{1} i_{d}+c_{2} i_{f}+c_{3} \psi_{D} \\
\frac{d i_{q}}{d t}=d_{1} i_{q}+d_{2} i_{d} \omega+d_{3} i_{f} \omega+d_{4} \omega \psi_{D}+d_{5} \psi_{Q}+d_{6} u_{q} \\
\frac{d \psi_{Q}}{d t}=f_{1} i_{q}+f_{2} \psi_{Q}
\end{gathered}
$$

where $u, i, \psi$ are current, voltage, and magnetic flux noted in rotor $(d q)$ coordinates,

$\omega$ is rotor speed,

and coefficients from $a_{1}$ to $f_{2}$ are given in Appendix A.

\subsection{Observer}

Deterministic observer of the system given in (1) is proposed:

$$
\frac{d \widehat{d_{d}}}{d t}=a_{1} i_{d}+a_{2} i_{f}+a_{3} i_{q} \omega+a_{4} \widehat{\psi_{D}}+a_{5} \widehat{\psi_{Q}} \omega+a_{6} u_{d}+a_{7} u_{f}+k_{11} e_{1}
$$




$$
\begin{gathered}
\frac{d \widehat{\psi_{D}}}{d t}=c_{1} i_{d}+c_{2} i_{f}+c_{3} \widehat{\psi_{D}}+k_{21} e_{1}+k_{22} e_{3} \\
\frac{d \widehat{\iota_{q}}}{d t}=d_{1} i_{q}+d_{2} i_{d} \omega+d_{3} i_{f} \omega+d_{4} \omega \widehat{\psi_{D}}+d_{5} \widehat{\psi_{Q}}+d_{6} u_{q}+k_{31} e_{3} \\
\frac{d \widehat{\psi_{Q}}}{d t}=f_{1} i_{q}+f_{2} \widehat{\psi_{Q}}+k_{41} e_{1}+k_{42} e_{3}
\end{gathered}
$$

where state errors are given:

$$
e_{1}=i_{d}-\widehat{\iota_{d}} ; e_{2}=\psi_{D}-\widehat{\psi_{D}} ; e_{3}=i_{q}-\widehat{\iota_{q}} ; e_{4}=\psi_{Q}-\widehat{\psi_{Q}}
$$

and convergence coefficients:

$$
k_{11} ; k_{21} ; k_{22} ; k_{31} ; k_{41} ; k_{42}
$$

The stability of the observer (2) is proved according to the positive definite Lyapunov function:

$$
V=\frac{e_{1}^{2}}{2}+\frac{e_{2}^{2}}{2}+\frac{e_{3}^{2}}{2}+\frac{e_{4}^{2}}{2}
$$

With (1) - (2), an error dynamics of the observer is:

$$
\begin{aligned}
\frac{d e_{1}}{d t} & =a_{4} e_{2}+a_{5} \omega e_{4}-k_{11} e_{1} \\
\frac{d e_{2}}{d t} & =c_{3} e_{2}-k_{21} e_{1}-k_{22} e_{3} \\
\frac{d e_{3}}{d t} & =d_{4} \omega e_{2}+d_{5} e_{4}-k_{31} e_{3} \\
\frac{d e_{4}}{d t} & =f_{2} e_{4}-k_{41} e_{1}-k_{42} e_{3}
\end{aligned}
$$

Using error dynamics (4), Lyapunov function (3) derivation becomes:

$$
\begin{aligned}
\dot{V}_{1} & =a_{4} e_{1} e_{2}+a_{5} \omega e_{1} e_{4}-k_{11} e_{1}^{2}+c_{3} e_{2}^{2}-k_{21} e_{1} e_{2}-k_{22} e_{2} e_{3}+ \\
& +d_{4} \omega e_{2} e_{3}+d_{5} e_{3} e_{4}-k_{31} e_{3}^{2}+f_{2} e_{4}^{2}-k_{41} e_{1} e_{4}-k_{42} e_{3} e_{4}
\end{aligned}
$$

After some algebra:

$$
\begin{array}{r}
\dot{V}_{1}=e_{1} e_{2}\left(a_{4}-k_{21}\right)+e_{1} e_{4}\left(a_{5} \omega-k_{41}\right)-k_{11} e_{1}^{2}+c_{3} e_{2}^{2}+ \\
+e_{2} e_{3}\left(d_{4} \omega-k_{22}\right)+e_{3} e_{4}\left(d_{5}-k_{42}\right)-k_{31} e_{3}^{2}+f_{2} e_{4}^{2}
\end{array}
$$

If the convergence coefficients are defined:

$$
k_{21}=a_{4} ; k_{41}=a_{5} \omega ; k_{22}=d_{4} \omega ; k_{42}=d_{5}
$$

Lyapunov function derivation becomes:

$$
\dot{V}=-k_{11} e_{1}^{2}+c_{3} e_{3}^{2}-k_{31} e_{3}^{2}+f_{2} e_{5}^{2}
$$

The parameters $c_{3}$ and $f_{2}$ are always negative due to character of the damper windings [11] [12]. If $k_{11}$ and $k_{31}$ coefficients are defined to be positive: 


$$
k_{11}=k_{31}=40
$$

then all elements of the expression (5.c) are negative definite, and Lyapunov function derivation is obtained:

$$
\dot{V}<0
$$

According to Lyapunov, positive definite Lyapunov function (3) with its negative definite derivation (5d) assures asymptotic stability of the observer (2).

\section{Linear Control System}

\subsection{Introduction}

To obtain linear control system, stator field oriented vector control principle is used. Electromagnetic torque is controlled by the referent stator current component $i_{T}$. Magnetic flux is controlled by the $i_{\psi}$ referent stator current component that is oriented in the stator field direction. To transfer from stator to rotor coordinates, the Park transformations is applied:

$$
\begin{aligned}
& i_{\text {dref }}=i_{\psi r e f} \cos \delta+i_{\text {Tref }} \sin \delta \\
& i_{\text {qref }}=-i_{\psi r e f} \sin \delta+i_{\text {Tref }} \cos \delta
\end{aligned}
$$

It could be seen that (6) needs calculation of the load angle $\delta$. Using observed (2) damper winding fluxes, stator fluxes could be easily obtained. Then, dividing stator flux components, load angle could be easily obtained:

$$
\delta=\operatorname{arctg} \frac{\psi_{q}}{\psi_{d}}
$$

where $\psi_{d}, \psi_{q}$ magnetic flux components of the stator winding.

In the Figure 1. The scheme of control system is given. It is cascaded system based on the stator current component inner loops and rotor speed and magnetic flux outer loops. Using stator and rotor currents and voltages, as well as rotor speed measurements, the control system is built. Controllers generate reference voltage that is applied onto the inverter by space vector modulation. Testing of the proposed control method is done for the exemplar SM which parameters are given in the Table 1. Computed dynamical system (1) for the used SM is given in Appendix B. 


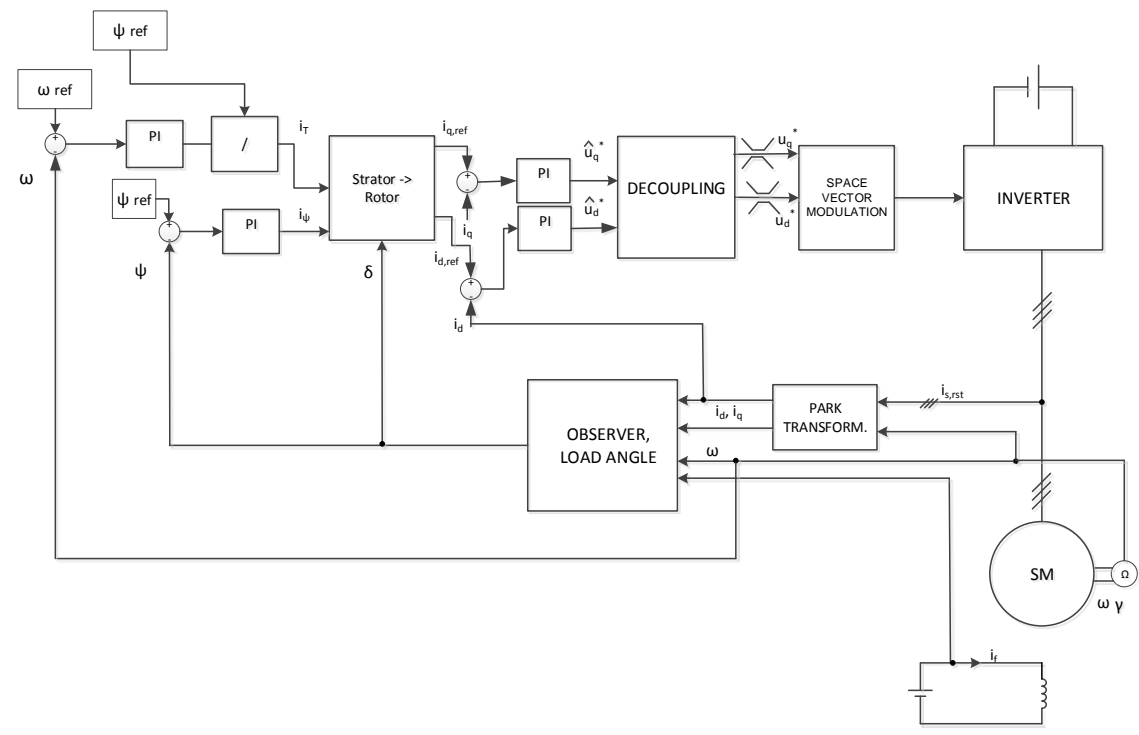

Figure 1

Control scheme

Table 1

Synchronous machine parameters

\begin{tabular}{|c|c|c|c|c|c|}
\hline Power & $S_{\mathrm{n}}(\mathrm{kVA})$ & 8.1 & $\begin{array}{l}\text { Rotor w. } \\
\text { resistance }\end{array}$ & $R_{\mathrm{f}}$ (p.u.) & 0.0612 \\
\hline Voltage & $U_{n}(\mathrm{~V})$ & 400 & $\begin{array}{l}\text { Rotor w. leak. } \\
\text { ind. }\end{array}$ & $L_{\sigma f}$ (p.u.) & 0.18 \\
\hline Pole pairs & $p$ & 2 & $\begin{array}{l}\text { Damper w. res. } \\
d \text {-axis }\end{array}$ & $R_{\mathrm{kD}}$ (p.u.) & 0.159 \\
\hline Frequency & $f_{\mathrm{n}}(\mathrm{Hz})$ & 50 & $\begin{array}{l}\text { Damper w. } \\
\text { leak.ind. } d \text {-axis }\end{array}$ & $\begin{array}{l}L_{\sigma \mathrm{kD}} \\
\text { (p.u.) }\end{array}$ & 0.117 \\
\hline $\begin{array}{l}\text { Stator w. } \\
\text { resistance }\end{array}$ & $R_{\mathrm{s}}($ p.u. $)$ & 0.082 & $\begin{array}{l}\text { Damper w. res. } \\
q \text {-axis }\end{array}$ & $R_{\mathrm{kQ}}$ (p.u.) & 0.242 \\
\hline Stator w. leak. ind. & $L_{\sigma}$ (p.u.) & 0.072 & $\begin{array}{l}\text { Damper w. } \\
\text { leak.ind. } q \text {-axis }\end{array}$ & $L_{\sigma \mathrm{kQ}}(\mathrm{p} . \mathrm{u})$. & 0.162 \\
\hline $\begin{array}{l}\text { Mutual ind. } d \text { - } \\
\text { axis }\end{array}$ & $L_{\mathrm{md}}$ (p.u.) & 1.728 & Inertia constant & $H(\mathrm{~s})$ & 0.14 \\
\hline $\begin{array}{l}\text { Mutual ind. } q \text { - } \\
\text { axis }\end{array}$ & $L_{\mathrm{mq}}$ (p.u.) & 0.823 & & & \\
\hline
\end{tabular}

\subsection{Stator Current Control}

Using (1a) and (1c), dynamics of the stator current components could be written:

$$
\frac{1}{a_{6}} \frac{d i_{d}}{d t}-\frac{a_{1}}{a_{6}} i_{d}=u_{d}+e_{d}
$$




$$
\frac{1}{d_{6}} \frac{d i_{q}}{d t}-\frac{d_{1}}{d_{6}} i_{q}=u_{q}+e_{q}
$$

where:

$$
\begin{array}{r}
e_{d}=\frac{a_{2} i_{f}+a_{3} i_{q} \omega+a_{4} \psi_{D}+a_{5} \psi_{Q} \omega+a_{7} u_{f}}{a_{6}} \\
e_{q}=\frac{d_{2} i_{d} \omega+d_{3} i_{f} \omega+d_{4} \omega \psi_{D}+d_{5} \psi_{Q}}{d_{6}}
\end{array}
$$

To obtain simplification, the following variables are introduced:

$$
\begin{aligned}
& \hat{u}_{d}=u_{d}-e_{d} \\
& \hat{u}_{q}=u_{q}-e_{q}
\end{aligned}
$$

Components $e_{d}, e_{q}$ are later used for obtaining decoupling, while stator current dynamics become linear differential equations of the first order:

$$
\begin{aligned}
& \hat{u}_{d}=a i_{d}+\frac{1}{a_{6}} \frac{d i_{d}}{d t} \\
& \hat{u}_{q}=d i_{q}+\frac{1}{d_{6}} \frac{d i_{q}}{d t}
\end{aligned}
$$

where:

$$
a=-\frac{a_{1}}{a_{6}} ; d=-\frac{d_{1}}{d_{6}}
$$

When the transformation into the Laplace domain is done, (11) become:

$$
\begin{aligned}
& G_{1}(s)=\frac{I_{d}(s)}{\widehat{U_{d}}(s)}=\frac{\frac{1}{a}}{\frac{1}{a a_{6}} s+1} \\
& G_{2}(s)=\frac{I_{q}(s)}{\widetilde{U_{q}}(s)}=\frac{\frac{1}{d}}{\frac{1}{d d_{6}} s+1}
\end{aligned}
$$

if:

$$
k_{p 1}=\frac{1}{a} ; \quad \tau_{p 1}=\frac{1}{a a_{6}} ; k_{p 2}=\frac{1}{d} ; \tau_{p 2}=\frac{1}{d d_{6}}
$$

stator current transfer functions could be noted:

$$
G(s)=\frac{k_{p}}{\tau_{p} s+1}
$$

Using IMC the transfer function of the IMC control of the stator current components could be derived:

$$
G_{c}(s)=\frac{k_{p}}{k_{p} \lambda} \frac{\tau_{p} s+1}{\tau_{p} s}
$$

If (14) is compared to a classical PI transfer function form:

$$
G_{P I}(s)=k_{c} \frac{\tau_{I} s+1}{\tau_{I} s}
$$


it could be concluded that IMC PI controller parameters are:

$$
\begin{aligned}
& k_{c}=\frac{\tau_{p}}{k_{p} \lambda} \\
& \tau_{I}=\tau_{p}
\end{aligned}
$$

In the $d$ axis the $i_{d}$ control is obtained. Proportional and integral parameters are given:

$$
\begin{aligned}
& k_{c 1}=\frac{\frac{1}{a a_{6}}}{\frac{1}{a} \lambda_{1}}=\frac{1}{\lambda_{1} a_{6}} \\
& k_{I 1}=\frac{k_{c 1}}{\tau_{I 1}}=\frac{k_{c 1}}{\frac{1}{a a_{6}}}
\end{aligned}
$$

In the $q$ axis the $i_{q}$ control is obtained. Proportional and integral parameters are given:

$$
\begin{gathered}
k_{c 2}=\frac{\frac{1}{d d_{6}}}{\frac{1}{d} \lambda_{2}}=\frac{1}{\lambda_{2} d_{6}} \\
k_{I 2}=\frac{k_{c 1}}{\tau_{I 2}}=\frac{k_{c 1}}{\frac{1}{d d_{6}}}
\end{gathered}
$$

where $\lambda_{1}, \lambda_{2}$ are used to obtain tuning of the current loops.

\subsection{Tuning}

Using SM parameters given in Table 1, controller gains could be computed. At first, gains for the current controls are:

$$
\begin{aligned}
& k_{c 1}=\frac{0,14}{\lambda_{1}} \\
& k_{I 1}=\frac{0,14}{0,824 \lambda_{1}} \\
& k_{c 2}=\frac{0,21}{\lambda_{2}} \\
& k_{I 2}=\frac{0,21}{0,83 \lambda_{2}}
\end{aligned}
$$

After few iterations $\lambda_{1}, \lambda_{2}$ are set as:

$$
\frac{1}{\lambda_{1}}=35 ; \frac{1}{\lambda_{2}}=28
$$

Then stator current gains could be finally calculated:

$$
\begin{aligned}
& k_{c 1}=5 ; k_{I 1}=6 \\
& k_{c 2}=6 ; k_{I 2}=7
\end{aligned}
$$

Then, using stator current gains, outer control loops are tuned using following procedure: 
1. Simulations with step up speed reference

a. $K_{p \psi}$ is increased enough to obtain the control of the stator flux and to achieve the electromagnetic torque has no oscillations. $K_{p \omega}$ is increased until the rotor speed could reach its nominal value. $K_{i \omega}, K_{p \psi}$ are set on zero value.

b. $\quad K_{p \omega}$ is then increased as much as it is needed for the rotor speed control to reach its critical point (oscilations)

c. Using Ziegler-Nichols method, parameters $K_{p \omega}, K_{i \omega}$ are callculated from the simulation results of the $b$.

2. Simulations with ramping rotor speed (real) reference:

a. $\quad K_{p \omega}, K_{i \omega}$ are used as calculated in 1.c and $K_{p \psi}$ is decreased as much as possible. Rotor speed tracking has to remain precise.

b. Magnetic flux stationary error is corrected by putting $K_{p \psi}$ on some value (ex. $K_{p \psi}=K_{i \psi}$ ).

c. Finally, $K_{i \omega}$ could be reduced until the control remain precise.

After the procedure, the outer loop gains are set as:

$$
\begin{gathered}
K_{p \omega}=120, K_{i \omega}=150 \\
K_{p \psi}=30, K_{i \psi}=30
\end{gathered}
$$

\section{Comparative Simulation}

\subsection{Introduction}

Matlab Simulink model of the DC/AC inverter drive is built. Inverter, VSI (Voltage Source Inverter) type, is used to obtain SM drive. Observer based linear control system comparison with nonlinear control system [11-12] is obtained. Load torque is assumed to be unknown disturbance for the linear control system. For the nonlinear control system, load torque is assumed to be known and its value is taken directly from the model. Therefore, some advantage is given to the nonlinear control system.

Control systems have been put in the same simulation model and the following SM dynamics have been obtained: starting under loaded condition, speed reversal under no load condition and step loading.

The aim is to control the rotor speed while maintaining stator flux at its nominal value. Tracking control has to be obtained, while the rotor speed reference is ramp. Control is obtained only through the stator voltage, while the rotor voltage is kept on its nominal value. 
Parameters of the novel linear control system PI controllers are set as is given in the Chapter 3.5, while the parameters of the nonlinear control systems are set:

$$
K_{\omega}=90, K_{\text {torque }}=20, K_{\psi}=25
$$

\subsection{Starting}

During starting process, load torque increase proportional to the rotor speed. When the nominal speed is reached at $1.5 \mathrm{~s}$, load torque reaches its nominal value of about 0.75 p.u. as it is given in Figure 8.

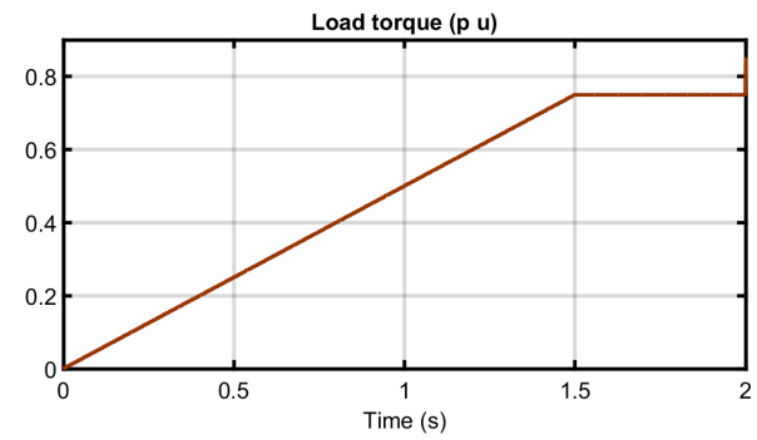

Figure 2

Starting - Load torque

In the Figure 3 performance of the damper winding flux observer (2) is shown. The observer is very precise.

Then, in the Figure 4, performances of both control systems are given. Precision of the rotor speed control is about equal, but precision of the stator flux control is better in the case of novel linear control.

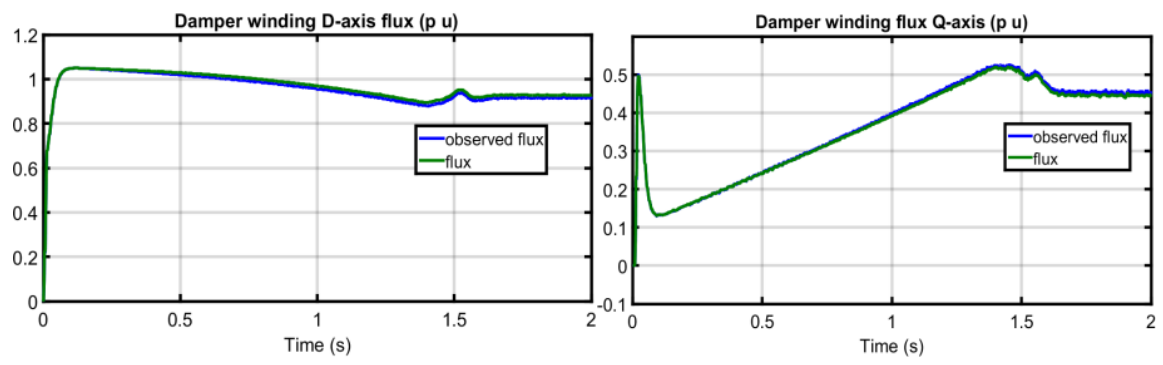

Figure 3

Starting - Observer performance 

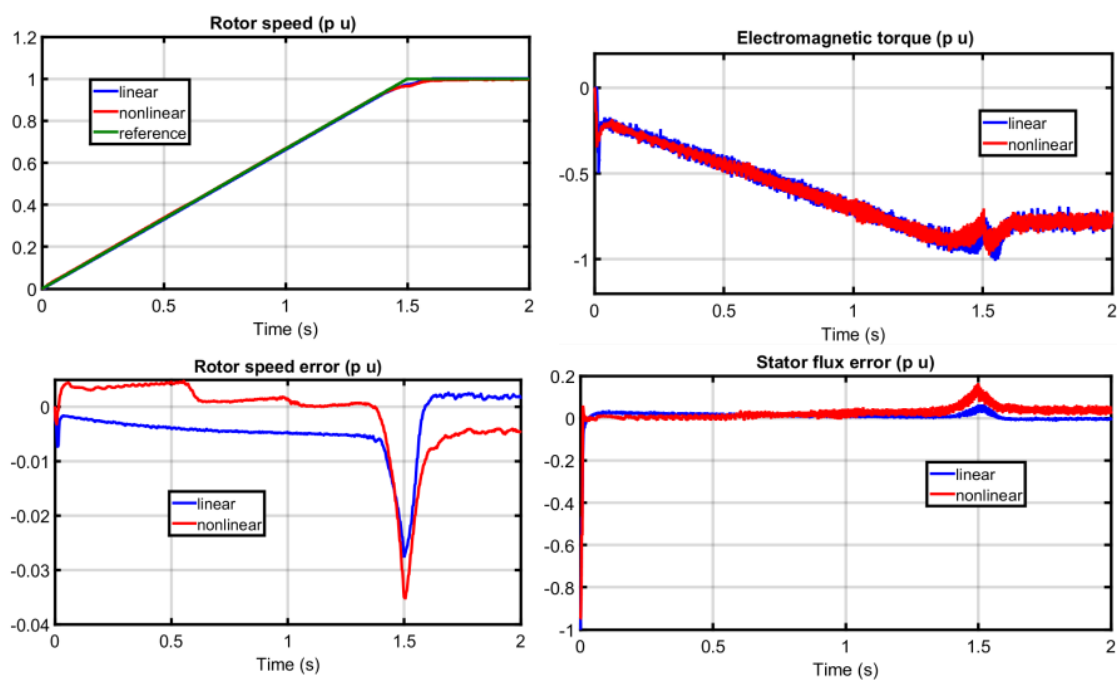

Figure 4

Starting - Control performance

\subsection{Speed Reversal}

Speed reversal is obtained without load torque. In that case, SM starting is shorter and ends at $1.0 \mathrm{~s}$. Observer performance is again precise as is given in Figure 5.

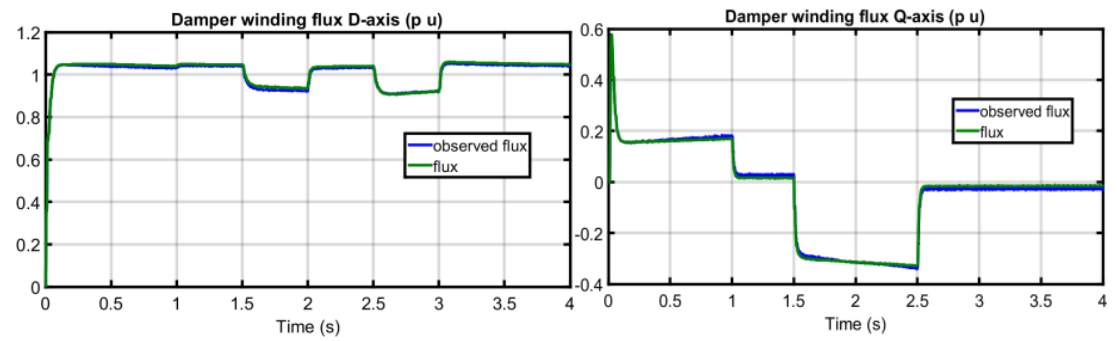

Figure 5

Speed reversal - Observer performance

Precision of the rotor speed control is about equal, but precision of the stator flux control is better in the case of novel linear control as is shown in Figure 6. 

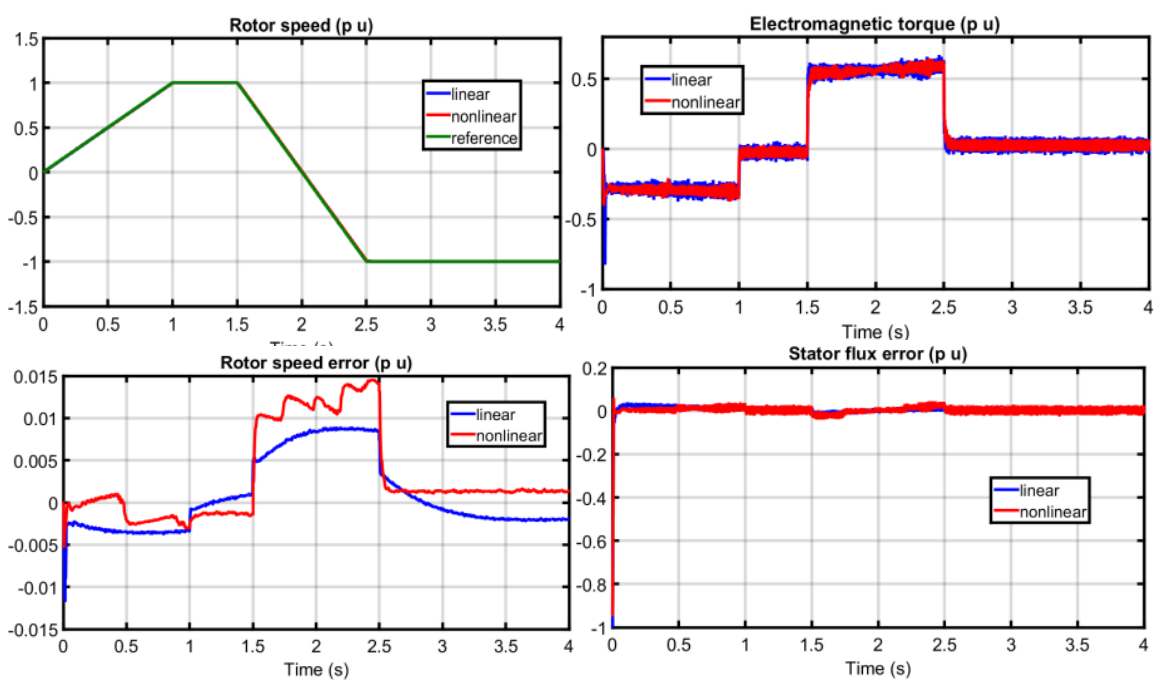

Figure 6

Speed reversal - Control performance

\subsection{Step Loading}

SM starting is obtained without loading. After reaching the nominal speed, the step loading and unloading (Figure 7) has been applied. The step has the value of the SM nominal load.

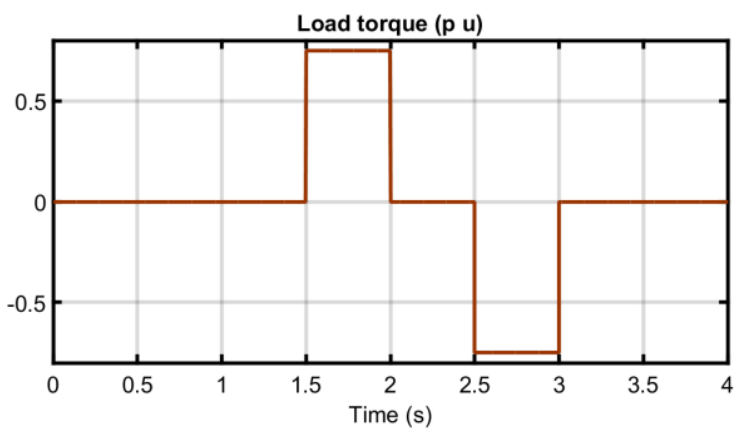

Figure 7

Step loading - Load torque

In spite of great load changes, observer performance is again precise as is shown in Figure 8. 


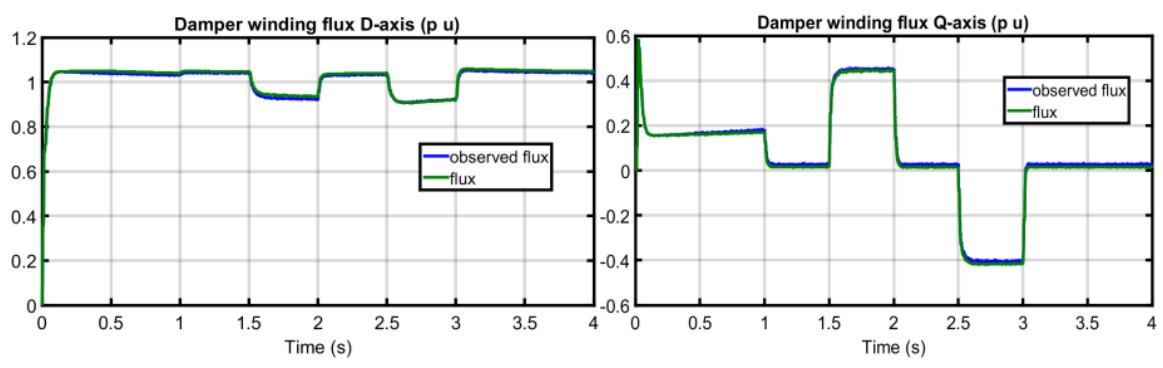

Figure 8

Step loading - Observer performance

Precision of the rotor speed control is about equal, but precision of the stator flux control is better in the case of novel linear control as is shown in Figure 9.
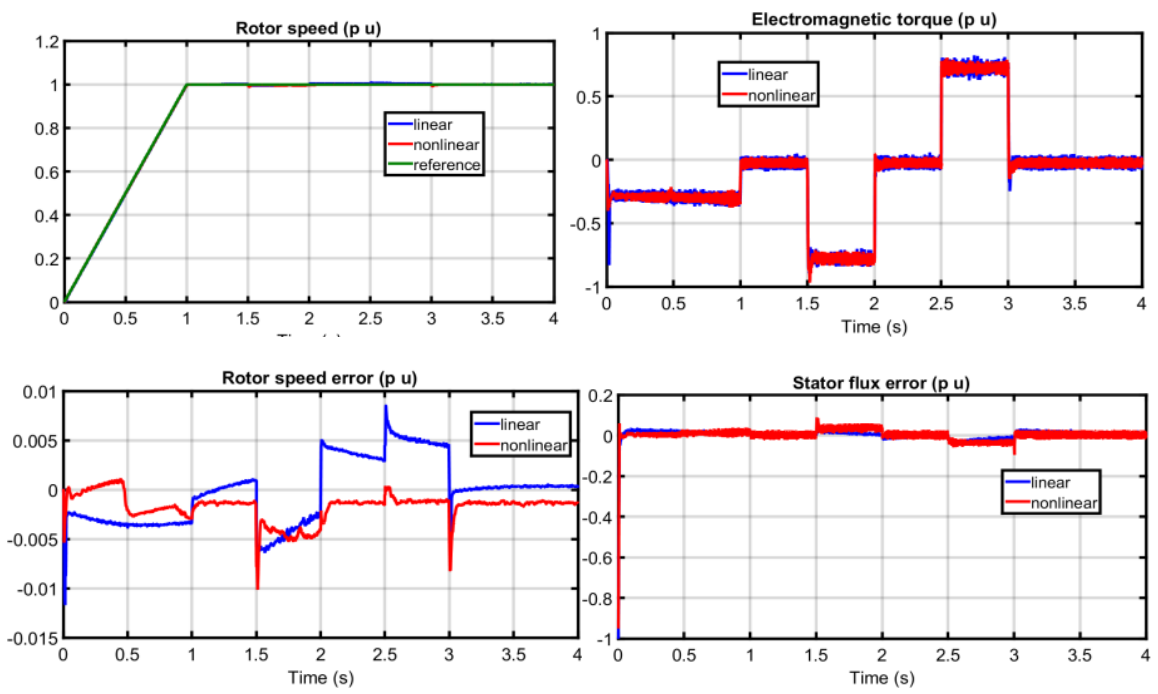

Figure 9

Step loading - Control performance

\subsection{Observer Comparison}

Operation of the novel and pure integration observer given in [11] [12] have been analyzed. Observers are applied in the same drive system and results for the starting, speed reversal and step loading have been given. Due to computational error there is some drift in dynamics of the pure integration observer. It especially occurs in D-axes as is shown during the starting process (Figure 10). Error of the novel observer is negligible. 

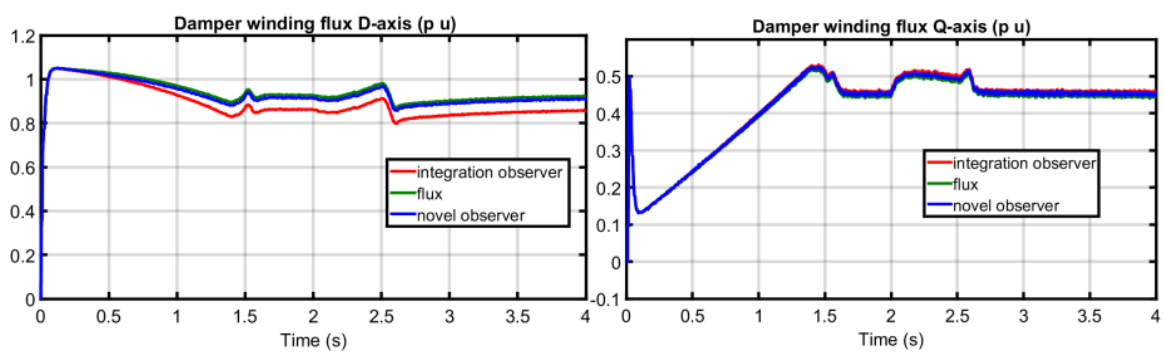

Figure 10

Starting - observer comparison

In the Figure 11 results for the dynamics of the speed reversal have been shown. Both observers perform precise operation, but better results are achieved by the novel flux observer.
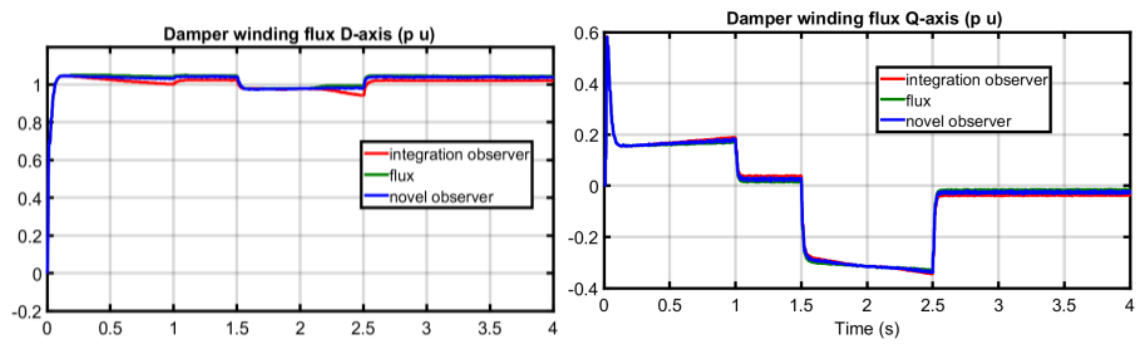

Figure 11

Speed reversal - observer comparison

During the step loading (Figure 12) some drift in D-axis flux could be again seen in pure integration observer, while the novel observer dynamics are precise.

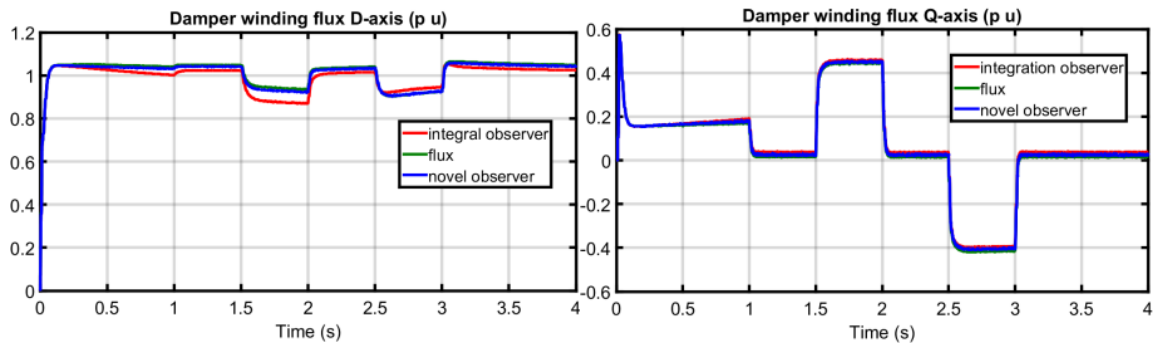

Figure 12

Step loading - observer comparison

\subsection{Controller Comparison}

Obtaining speed reversal simulations, influence of the controller has been analyzed. At first it is shown that performance of the nonlinear controller could not be improved much if the integration observer [11] [12] is replaced by the 
novel observer. As is shown in Figure 13, novel observer reduces nonlinear control performance error only for a bit.
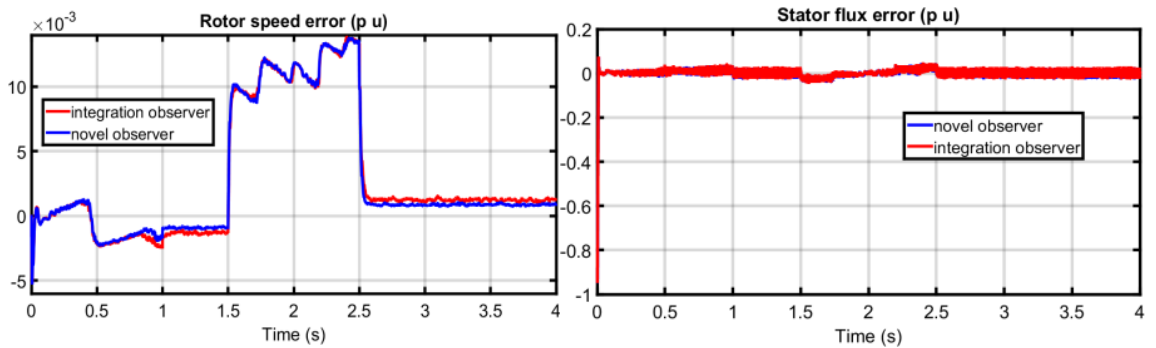

Figure 13

Speed reversal - nonlinear controller using different observers

Performance of the novel linear control has been tested when it uses different observers. Due to the error of the integration observer, rotor speed error increases as it is shown in Figure 14.
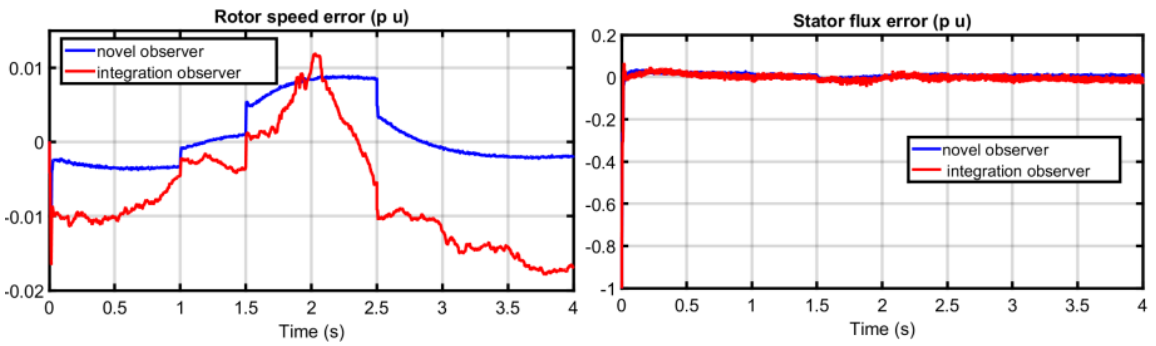

Figure 14

Speed reversal - novel controller using different observers

It could be concluded that novel linear control backed by the novel flux observer gives the best control performance.

\subsection{Robustness of the Control System}

To obtain robustness-testing, variation of the SM parameters has been done. Step loading simulations in the cases of inductances increase and inductance decrease have been obtained. In the case of the main SM inductance 15 percent increase, results are shown in the Figure 15. During the load torque step-up, nonlinear control performance deteriorates. Novel linear control performance remains precise. 

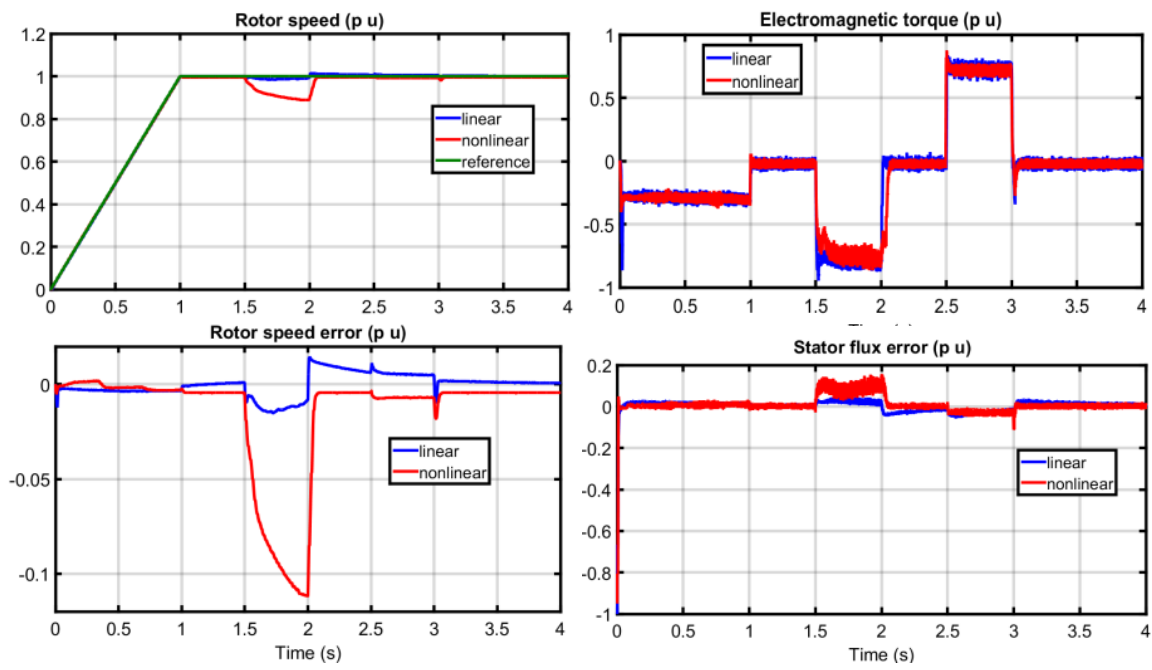

Figure 15

Step loading - increased inductance

In the case of the main SM inductance 15 percent decrease, results are shown in the Figure 16. Novel linear control system shows better results in both: rotor speed and stator flux control.
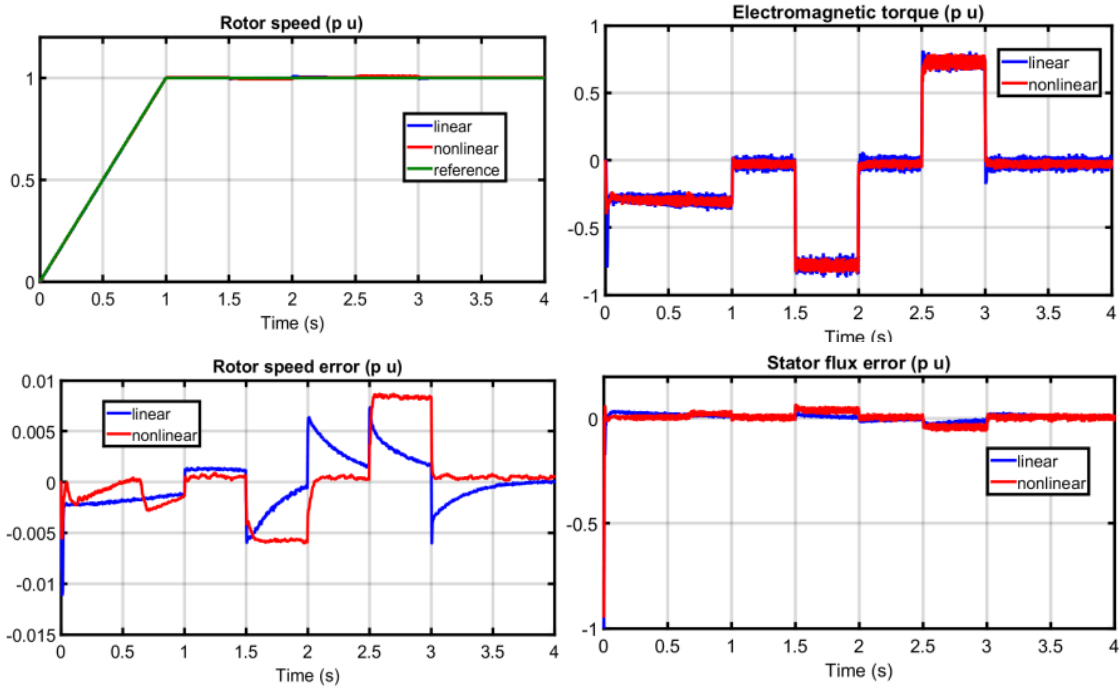

Figure 16

Step loading - decreased inductance 


\section{Conclusions}

There is still room for improvement, in the research field of SM control. Linear control studies usually fail to take into consideration all complexities of the SM dynamical system. Nonlinear control studies are usually predictive control laws that need to know all system states, inputs and disturbances. Specially, precise information about the load torque is sometimes hard to obtain.

Based on the given deterministic observer and linear control analysis, a novel control method has been presented in this work. Without any need for predictive information and without any knowledge about load torque the novel control systems obtains high performance.

To obtain adequate comparison, simulation studies for an exemplar SM have been done. Dynamical responses in the cases of SM starting, speed reversal, and step loading have been compared to results of the nonlinear control. Results show that novel deterministic observer gives better results than the existing one. It is also shown that novel control gives equal or better results than nonlinear control. Finally, it could be concluded, that due to all mentioned advantages, the novel control system is preferred for use in praxis.

\section{Acknowledgement}

This work was supported by Končar Power Plant and Electric Traction Engineering and Končar Electrical Engineering Institute.

\section{Reference}

[1] J. Pyrhonen, V. Hrabcova, R. S. Semken: Electrical Machine Drives Control - An Introduction. Wiley, 2016

[2] D. Beliaev, E. Ilyin, A. Shatokhin, A. Weinger: "Synchronous drives with field oriented vector control and their industrial implementation", Proceedings of the IEEE Conference on Power Eletronics and Applications, EPE'09, Barcelona, Spain, September 2009, pp. 1-10

[3] M. Imecs, I. I. Incze, C. Szabo: "Stator-Field Oriented Control of the Synchronous Generator: Numerical simulation", Proceedings of the IEEE Conference on Intellingent Engineering Systems, INES, Miami, USA, Feb. 2008, pp. 93-98

[4] C. Szabo, M. Imecs, I. I. Incze: "Synchronous Motor Drive with Controlled Stator-Field-oriented Longitudinal Armature Reaction", The $33^{\text {th }}$ International Conference of the IEEE Industrial Electronics Society, IECON 2007, Taipei, Taiwan, pp. 1214-1219

[5] M. Imecs, C. Szabo, I. I. Incze: "Stator-Field-Oriented Vectorial Control for VSI-Fed Wound-Excited Synchronous Motor", Proceedings of the IEEE Aegean Conference on Electrical Machine and Power Electronics ACEMP, Bordum, Turkey, 2007, pp. 303-308 
[6] C. Szabo, M. Imecs, I. I. Incze: "Vector control of the synchronous motor operating at unity power factor", Proceedings of the IEEE Conference on optimization of Electrical and Electronic Equipment, Brasov, Romania May 2008, pp. 15-20

[7] M. Imecs C. Szabo I. I. Incze: "Stator-Field Oriented Control of the Variable-excited Synchronous Motor: Numerical simulation", $7^{\text {th }}$ International Symposium of Hungarian Researches on Computational Intelligence, Budapest, Hungary, Nov. 2006, pp. 95-106

[8] J. Kaukonen: "Salient pole synchronous machine modelling in a industrial direct torque controlled drive application", $\mathrm{PhD}$ Thesis, Lappeenrata University of Technology, Finland, 1999

[9] R. Marino, P. Tomei, C. M. Verrelli: "Nonlinear Control for SpeedSensorless Synchronous Motors with Damping Windings", Proceedings of the IEEE Conference on Power Engineering, Energy and Electrical Devices, Setubal, Portugal, 2007, pp. 742-747

[10] R. Marino, P. Tomei, C. M. Verrelli: "Adaptive Field-oriented Control of Synchronous Motors with Damping Windings", European Journal of Control, 2008(3), pp. 177-195

[11] M. Šundrica, I. Erceg, Z. Maljković: "Nonlinear observer based control of synchronous machine drive system", Journal of Electrical Engineering \& Technology, 2015, 10(3), pp. 1035-1047

[12] M. Šundrica: „Synchronous Machine Nonlinear Control System Based on Feedback Linearization and Deterministic Observers", In C. Volosencu editor: Control Theory in Engineering, IntechOpen 2019, pp. 1-23

[13] C. Pozna, R-E Precup:"An Aproach to the Design of Nonlinear State-Space Control Systems", Studies in Informatics and Control, 27(1), March 2018, pp. 5-14

[14] A. Takacs, I. J. Rudas, L. Kovacs, R-E Precup:"Models for Force Control in Telesugical Robot Systems", Acta Polytechnica Hungarica, Vol. 12, No. 8, 2015, pp. 95-114

[15] A. Takacs, I. J. Rudas, L. Kovacs, R-E Precup:”Artificial cognitive control system based on shared circuits model of sociocognitive capacities. A first aproach”, Engineering Applications of Artificial Intelligence, 12(1) March 2011, pp. 209-219

[16] J. Samuel, P. Jimoh: "Neural Network-Based Adaptive Feedback Linearization Control of Antilock Braking System", International Journal of Artificial Intelligence, Vol. 10, No. S13, Spring(March) 2013, pp. 21-40

[17] R. R. Yacoub, A. Harsoyo, R. T. Bambang, J. Sarwono: "DSP implementation of combined FIR-functional link neutral network for active noise control", International Journal of Artificial Intelligence, 12(1), March 2014, pp. 36-47 
[18] S. Blažič: "On Periodic Control Laws for Mobile Robots", IEEE Transactions on Industrial Electronics, Vol. 61, No. 7, July 2014, pp. 36603670

[19] R-C. Roman, R-E Precup, C-A Bojan-Dragos, A-I Szedlak-Stinean: "Combined Model-Free Adaptive Control with Fuzzy Component by Virtual Reference Feedback Tuning for Tower Crane Systems", Procedia Computer Science 162 (2019), pp. 267-274

\section{Appendix A}

Coefficients of synchronous machine dynamical model given in (1):

$$
\begin{aligned}
& a_{1}=\frac{L_{f} L_{m d}{ }^{2} R_{D}-L_{m d}{ }^{3} R_{D}-L_{D}{ }^{2} L_{f} R_{s}+L_{D} L_{m d}{ }^{2} R_{s}}{L_{D}\left(-L_{d} L_{D} L_{f}+L_{d} L_{m d}{ }^{2}+L_{D} L_{m d}{ }^{2}+L_{f} L_{m d}{ }^{2}-2 L_{m d}{ }^{3}\right)} \\
& a_{2}=\frac{-L_{f} L_{m d}{ }^{2} R_{D}+L_{m d}{ }^{3} R_{D}+L_{D}{ }^{2} L_{m d} R_{f}-L_{D} L_{m d}{ }^{2} R_{f}}{L_{D}\left(-L_{d} L_{D} L_{f}+L_{d} L_{m d}{ }^{2}+L_{D} L_{m d}{ }^{2}+L_{f} L_{m d}{ }^{2}-2 L_{m d}{ }^{3}\right)} \\
& a_{3}=\frac{L_{D}{ }^{2} L_{f} L_{m q}{ }^{2}-L_{D} L_{m d}{ }^{2} L_{m q}{ }^{2}-L_{D}{ }^{2} L_{f} L_{q} L_{Q}+L_{D} L_{m d}{ }^{2} L_{q} L_{Q}}{L_{D} L_{Q}\left(-L_{d} L_{D} L_{f}+L_{d} L_{m d}{ }^{2}+L_{D} L_{m d}{ }^{2}+L_{f} L_{m d}{ }^{2}-2 L_{m d}{ }^{3}\right)} \\
& a_{4}=\frac{L_{f} L_{m d} L_{Q} R_{D}-L_{m d}{ }^{2} L_{Q} R_{D}}{L_{D} L_{Q}\left(-L_{d} L_{D} L_{f}+L_{d} L_{m d}{ }^{2}+L_{D} L_{m d}{ }^{2}+L_{f} L_{m d}{ }^{2}-2 L_{m d}{ }^{3}\right)} \\
& a_{5}=\frac{L_{D}{ }^{2} L_{f} L_{m q}-L_{D} L_{m d}{ }^{2} L_{m q}}{L_{D} L_{Q}\left(-L_{d} L_{D} L_{f}+L_{d} L_{m d}{ }^{2}+L_{D} L_{m d}{ }^{2}+L_{f} L_{m d}{ }^{2}-2 L_{m d}{ }^{3}\right)} \\
& a_{6}=\frac{L_{D}{ }^{2} L_{f} L_{Q}-L_{D} L_{m d}{ }^{2} L_{Q}}{L_{D} L_{Q}\left(-L_{d} L_{D} L_{f}+L_{d} L_{m d}{ }^{2}+L_{D} L_{m d}{ }^{2}+L_{f} L_{m d}{ }^{2}-2 L_{m d}{ }^{3}\right)} \\
& a_{7}=\frac{-L_{D}{ }^{2} L_{m d} L_{Q}+L_{D} L_{m d}{ }^{2} L_{Q}}{L_{D} L_{Q}\left(-L_{d} L_{D} L_{f}+L_{d} L_{m d}{ }^{2}+L_{D} L_{m d}{ }^{2}+L_{f} L_{m d}{ }^{2}-2 L_{m d}{ }^{3}\right)} \\
& c_{1}=-\frac{L_{m d} R_{D}}{L_{D}} \\
& c_{2}=\frac{L_{m d} R_{D}}{L_{D}} \\
& c_{3}=-\frac{R_{D}}{L_{D}} \\
& d_{1}=\frac{-L_{D} L_{m q}{ }^{2} R_{Q}+L_{D} L_{Q}{ }^{2} R_{S}}{L_{D} L_{Q}\left(-L_{m q}{ }^{2}+L_{q} L_{Q}\right)} \\
& d_{2}=\frac{-L_{d} L_{D} L_{Q}{ }^{2}+L_{m d}{ }^{2} L_{Q}{ }^{2}}{L_{D} L_{Q}\left(-L_{m q}{ }^{2}+L_{q} L_{Q}\right)}
\end{aligned}
$$




$$
\begin{aligned}
& d_{3}=\frac{L_{D} L_{m d} L_{Q}{ }^{2}-L_{m d}{ }^{2} L_{Q}{ }^{2}}{L_{D} L_{Q}\left(-L_{m q}{ }^{2}+L_{q} L_{Q}\right)} \\
& d_{4}=\frac{L_{m d} L_{Q}}{L_{D}\left(-L_{m q}{ }^{2}+L_{q} L_{Q}\right)} \\
& d_{5}=\frac{-L_{m q} R_{Q}}{L_{Q}\left(-L_{m q}{ }^{2}+L_{q} L_{Q}\right)} \\
& d_{6}=\frac{-L_{Q}}{\left(-L_{m q}{ }^{2}+L_{q} L_{Q}\right)} \\
& f_{1}=-\frac{L_{m q} R_{Q}}{L_{Q}} \\
& f_{2}=-\frac{R_{Q}}{L_{Q}}
\end{aligned}
$$

\section{Appendix B}

Computed dynamical system (1) of the used synchronous machine:

$$
\begin{gathered}
\frac{d i_{d}}{d t}=-1,2 i_{d}-0,45 i_{f}+1,48 i_{q} \omega+0,36 \psi_{D}+5,96 \psi_{Q} \omega+7,13 u_{d}-2,7 u_{f} \\
\frac{d \psi_{D}}{d t}=0,15 i_{d}+0,15 i_{f}-0,09 \psi_{D} \\
\frac{d i_{q}}{d t}=-1,21 i_{q}-0,88 i_{d} \omega-0,53 i_{f} \omega-4,52 \omega \psi_{D}+0,9 \psi_{Q}+4,82 u_{q} \\
\frac{d \psi_{Q}}{d t}=0,2 i_{q}-0,25 \psi_{Q}
\end{gathered}
$$

